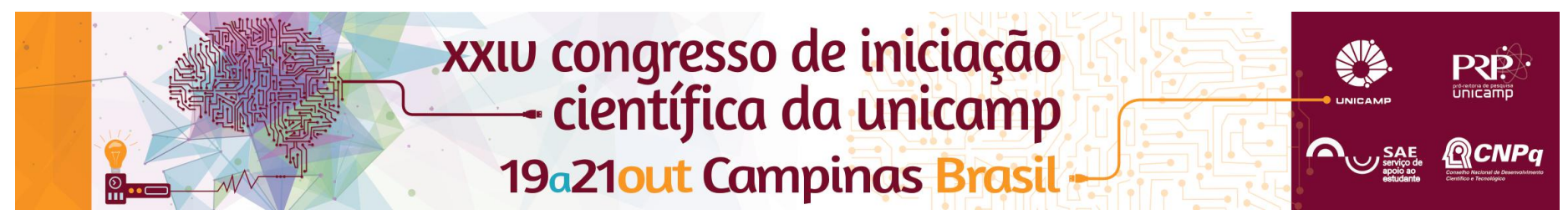

\title{
Influência do conteúdo de partículas bioativas na adesão bacteriana e biodegradação de infiltrantes resinosos experimentais.
}

\section{Enrico Angelo*, Maurício Matté Zanini, Lourenço Correr-Sobrinho, Mário Alexandre Coelho Sinhoreti, Américo Bortolazzo Correr}

\section{Resumo}

O objetivo neste estudo foi avaliar a biodegradação de infiltrantes experimentais com diferentes tipos e concentrações de partículas bioativas, através de avaliações de rugosidade (Ra). A partir de uma formulação base composta de BisEMA e TEGDMA foram adicionadas partículas de hidroxiapatita (Hap); fosfato de cálcio amorfo (ACP); biovidro dopado com Zn (BAG-Zn) e partículas de cimento de silicato de cálcio modificado por $\beta$-tricálcio fosfato ( $\beta$-TCP). As partículas foram adicionadas nas concentrações de 1\%,5\% e 10\% em peso. No grupo controle não foram adicionadas partículas. Cinco discos (5mm de diâmetro X $1 \mathrm{~mm}$ de espessura) de cada material foram confeccionados e a rugosidade avaliada antes e após biodegradação por 7 dias de contato com o biofilme artificial de Streptococcus mutans. Os dados foram avaliados por ANOVA de medidas repetidas e teste de Tukey $(\alpha=5 \%)$.

Palavras-chave: infiltrantes, antibacteriano, degradação

\section{Introdução}

Tem sido relatado na literatura que as resinas acumulam mais bactérias viáveis ou biofilme que outros materiais restauradores (Padovani et al., 2015; Padovani et al., 2014; Spencer et al., 2014), devido a sua baixa atividade antibacteriana. $\mathrm{O}$ acúmulo de biofilme sobre a resina pode levar a degradação dos material ao longo do tempo (Spencer et al., 2014) e ao desenvolvimento de cárie secundárias, reduzindo a vida útil da técnica de infiltração.

Um trabalho recente mostrou que a adição de micropartículas não prejudicou a infiltração dos infiltrantes nas lesões de cárie (Askar et al., in press). Assim, a incorporação de quantidades adequadas de agentes antibacterianos poderia fornecer aos infiltrantes atividade sobre o biofilme, sem influenciar negativamente suas propriedades mecânicas (Wang et al., 2014).

Os infiltrantes são utilizados com o objetivo de ocluir as porosidades causadas pela cárie, mas não tem sido relatado qualquer efeito antibacteriano no substrato dental causado por estes materiais. Assim, a associação destas resinas de baixa viscosidade com partículas bioativas seria benéfica para bloquear a progressão da cárie, reparar os danos causados pela lesão e atuar como agente antibacteriano.

Assim, o objetivo nesse estudo é avaliar a atividade antimicrobiana e a biodegradação de infiltrantes resinosos experimentais, com adição de diferentes concentrações e tipos de partículas bioativas.

\section{Resultados e Discussão}

Foram formuladas blendas resinosas contendo $75 \%$ (peso) de trietilenoglicol dimetacrilato (TEGDMA) (SigmaAldrich Inc., St. Louis, MO, USA) e 25\% (peso) de bisfenol etoxilado dimetacrilato (BisEMA) (Sigma Aldrich). Nesta formulação foram adicionados como sistema fotoiniciador $0,5 \%$ em peso de canforquinona (CQ) (Sigma-Aldrich) e $1 \%$ (peso) de dimetilaminoetil metacrilato (DMAEMA) (Sigma- Aldrich). Além disso, foi adicionado à mistura o inibidor BHT (hidroxitolueno) $(0,1 \%)$ (Sigma) para prevenir a polimerização espontânea da resina.

A partir desta formulação resinosa foram adicionadas as partículas de Hidroxiapatita (Sigma-Aldrich Inc., St Louis, MO, USA), fosfato de cálcio amorfo (Sigma-Aldrich Inc., St. Louis, MO, USA), partículas de vidro bioativas (BAG-Zn) e cimento de silicato de cálcio modificado por $\beta$ tricálcio fosfato (HCAT- $\beta$ ) nas concentrações de $1 \%, 5 \%$ e $10 \%$ em peso. Os infiltrantes experimentais foram agitados por 24 horas para homogeneização dos componentes previamente ao uso.

$\mathrm{Na}$ avaliação inicial observou-se que a Ra de ACP foi significativamente maior que HAP e BAG-Zn; inicialmente a Ra de $5 \%$ foi maior que $1 \%$. Antes da biodegradação os grupos ACP $5 \%$ e HAP1\% diferiram do controle. Após a biodegradação os resultados mostraram que: 1.houve redução significativa da Ra para todos os grupos; 2 . Não houve diferença entre as concentrações; 3 . Não houve diferença entre os materiais com partículas; 4 . Todos os materiais diferiram do controle.

\section{Conclusões}

Conclui-se que a biodegradação reduziu a rugosidade dos infiltrantes, independente do tipo e concentração de partícula bioativa.

\section{Agradecimentos}

Agradecimento ao CNPq e à Área de Ofdontopediatria da FOP-Unicamp.

1. Padovani GC, Fùcio SB, Ambrosano GM, Correr-Sobrinho L, Puppin-Rontani RM. In situ bacterial accumulation on dental restorative materials CLSM/COMSTAT analysis. Am J Dent. 2015 Feb;28(1):3-8.

2. Padovani G, Fúcio S, Ambrosano G, Sinhoreti M, Puppin-Rontani R. In situ surface biodegradation of restorative materials. Oper Dent. 2014 JulAug;39(4):349-60.

3. Spencer P, Ye Q, Misra A, Goncalves SE, Laurence JS. Proteins, pathogens, and failure at the composite-tooth interface. J Dent Res. 2014 Dec;93(12):1243-9. 4. Askar H, Lausch J, Dörfer CE, Meyer-Lueckel H, Paris S. Penetration of micro- filled infiltrant resins into artificial caries lesions. J Dent. 2015 In press doi:10.1016/j.jdent.2015.03.002.

5. Wang Z, Shen Y, Haapasalo M. Dental materials with antibiofilm properties Dent Mater. 2014 Feb;30(2):e1-16. 